\title{
Evaluation of Anti Arthritic Potential of Gloriosa superba (L.) Elite Germplasm Collected from Eastern Himalayas, India
}

\author{
Ankita Misra ${ }^{1,2}$ Akanksha Srivastava $^{1}$, Mohammad Khalid ${ }^{2}$, Poonam Kushwaha ${ }^{2}$, Sharad Srivastava ${ }^{1 *}$
}

\section{Ankita Misra ${ }^{1,2}$ Akanksha Srivastava ${ }^{1}$, Móhammad Khalid², Poonam Kushwaha², Sharad Srivastava ${ }^{1 *}$}

'Pharmacognosy and Ethnopharmacology Division, CSIR-National Botanical Research Institute, Lucknow, Uttar Pradesh 226001, INDIA.

${ }^{2}$ Faculty of Pharmacy, Integral University, Lucknow, Uttar Pradesh 226001, INDIA.

\section{Correspondence}

\section{Dr. Sharad Srivastava}

Pharmacognosy and Ethnopharmacology Division, CSIR-National Botanical Research Institute, Lucknow Uttar Pradesh 226001, INDIA.

Phone No: 91-522-2297818

E-mail: sharad_ks2003@yahoo.com

\section{History}

- Submission Date: 02-10-2017

- Review completed: 02-11-2017;

- Accepted Date: 09-11-2017

\section{DOI : 10.5530/pj.2017.6s.162}

Article Available online http://www.phcogj.com/v9/i6

\section{Copyright}

(C) 2017 Phcog.Net. This is an openaccess article distributed under the terms of the Creative Commons Attribution 4.0 International license.

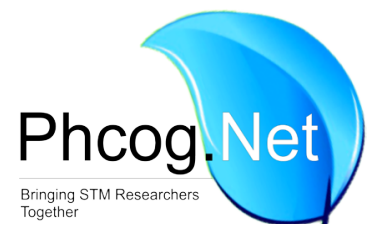

\begin{abstract}
Introduction: Gloriosa superba (L.) is a traditionally known medicinal plant for its potential antigout property. The species is rich source of colchicine alkaloid and is commercially exploit in the international market for the same. Method: In the present study, elite chemotype of G. superba was identified from natural population in Eastern Himalayas based on their colchicine content through HPTLC calibrated method. The selected elite chemotypes were further evaluated for in vitro anti-arthritic potential via inhibition of protein denaturation along with hydroxyl radical scavenging potential. Result: The HPTLC quantification data reveals that the content of colchicine varies from 0.044 to $0.184 \%$ having maximum content in NBG-128 from Jorhat, Assam. The results of bioassay reflect a potentiating anti-arthritic and hydroxyl radical scavenging with statistically insignificant difference within the elite germplasms. Conclusion: The presence of bioactive polyphenolics with significant hydroxyl radical scavenging will further suggest that inhibition of inflammatory mediator cells by extract is superimposed action of colchicine and other chemical inhibitors like polyphenolics. The study will aid in site specific exploration of high metabolite yielding chemotype(s) with validated pharmacological action for commercial cultivation to meet out the industrial demand of colchicine and herbal product development
\end{abstract}

Key words: G. superba, Colchicine, Elite chemotype, HPTLC, Anti arthritic.

\section{INTRODUCTION}

Gloriosa superba L. (Colchicaceae) is a tuberous climbing herb found throughout tropical parts of India up to an altitude of $1800 \mathrm{~m}$ and also distributed in other tropical parts of the World. Indigenously Gloriosa is known as 'kalihari' in Hindi, 'Agnishikha' in Sanskrit and its trade name is "Glory lily". The species exhibits various medicinal properties viz. analgesic, anti-inflammatory, antimicrobial, larvicidal, antipoxviral, antithrombotic, antitumor and, also used in treatment of snake bite, gout, respiratory disorders. . $^{2,3,4}$

Gloriosa superba is a potential source of phenethylisoquinoline category of alkaloids, among which colchicine is the major metabolite for which Gloriosa is industrially exploited from time long and hence became a threatened species. Other chemical constituents in tubers are lumicolchicine, 2-demethylcolchicine, 3-demethylcolchicine, N-formyl-N-deacetyl-colchicine, benzoic acid, salicylic acid, sterols, resinous substances, colchicoside, gloriosine, tannins and superbine., 5

The chemotaxonomic studies of G. superba were scarcely documented. ${ }^{7,8,9}$ We had reported the variations of colchicine content in G. superba L., germplasms collected from Central India using OPLC technique. ${ }^{10}$ The use of colchicine in gout was well established by severalbiochemicalandclinicalstudies, ${ }^{11,12,13,14,15}$ however scientific validation of G. superba for its traditional claim in gouty arthritis is still very less. ${ }^{16}$ Thus, looking towards the commercial relevance of colchicine, the study was aimed to record the intra-specie variation in colchicine content of G. superba population from Eastern Himalayas. This was further extended to validate the pharmacological potential i.e. antiarthritic activity of elite germplasm selected from the population. In addition, antioxidant activity of elite germplasms was also established. This will aid in site specific exploration of high colchicine yielding chemotype(s) with validated pharmacological action to meet out the medicinal and commercial demands.

\section{MATERIALS AND METHODS}

\section{Chemicals and reagents}

Colchicine (99.8\% w/w), Bovine Serum Albumin (BSA flakes, >99.8 \%) were purchased from SigmaAldrich (St. Louis, MO, USA). Solvents, viz. chloroform, acetone, and diethyl amine of analytical grade, are obtained from Merck, Mumbai (India). Solvents were filtered $(0.45 \mathrm{~mm}$ filter, Millipore, Bedford, MA, USA) and sonicated for $15 \mathrm{~min}$ before use. HPTLC $(20 \mathrm{~cm} \times 20 \mathrm{~cm})$, precoated silica gel alumi- 
num plates $60 \mathrm{~F}_{254},(0.25 \mathrm{~mm})$ were purchased from Merck (Darmstadt, Germany).

\section{Plant material and extraction protocol}

The tubers were collected during the month of September from NorthEastern Himalayan region covering Sikkim and the adjoining area of West Bengal. Five samples were collected from varied condition(s); specimens were authenticated and deposited in repository of CSIRNBRI with individual voucher number. GPS information of the collected samples is recorded and summarized in Table 1.

The samples were washed with water, chopped, and shade dried. The dried tubers were coarsely powdered by passing through 40 mesh sieves (up to $500 \mathrm{~mm}$ ), and the powdered sample (about $5 \mathrm{~g}$ ) is defatted using petroleum ether by maceration method (cold) to remove the fatty materials/impurity. The defatted material was then macerated (cold method) with methanol $(25 \mathrm{ml})$ for $24 \mathrm{~h}$ at room temperature $\left(25^{\circ} \mathrm{C} \pm 2^{\circ} \mathrm{C}\right)$ for 3 consecutive days. Extraction was repeated thrice, filtered (Whatman no. 4), and the pooled filtrate was dried in a rotatory evaporator (Buchi, USA) under standard conditions of temperature $\left(55^{\circ} \mathrm{C} \pm 2^{\circ} \mathrm{C}\right)$ and pressure (40 mbar). The concentrated extract was finally lyophilized to solid residue (Labconco, USA).

\section{HPTLC quantification of bioactive metabolite colchicine}

The collected samples of G. superba were quantified for bioactive alkaloid(s), colchicine through HPTLC calibrated method as per ICH guidelines (2005). ${ }^{17}$ Quantified markers are expressed as \% dry weight of crude samples.

\section{In vitro anti-oxidant activity}

Estimation of total phenolics

Assay of total phenolic ${ }^{18}$ (TPC) and total flavonoid ${ }^{19}$ (TFC) content was quantified by spectroscopic method as per standard protocol based on regression curve of reference standard. Total phenolic and flavonoid content was expressed in $\mathrm{mg} / \mathrm{g}$ of gallic acid equivalent (GAE) and quercetin equivalent (QE).

\section{Hydroxyl radical scavenging activity (HRSA)}

Hydroxyl radical scavenging activity of samples was determined according to the standard method ${ }^{20}$ with slight modification. The reactive mixture, containing methanolic extract $(0.2 \mathrm{mg} / \mathrm{ml})$ in variable concentration $(20-100 \mu \mathrm{l})$ was incubated with $0.1 \mathrm{ml}$ EDTA $(0.1 \mathrm{mM}), 0.01 \mathrm{ml}$ of ferric chloride $(10 \mathrm{mM}), 0.36 \mathrm{ml}$ of deoxy ribose $(10 \mathrm{mM}), 0.33 \mathrm{ml}$ of phosphate buffer $(\mathrm{pH} 7.9,50 \mathrm{mM})$ and $0.1 \mathrm{ml}$ ascorbic acid $(1 \mathrm{mM})$. The reaction was initiated by addition of $0.1 \mathrm{ml}$ of $\mathrm{H}_{2} \mathrm{O}_{2}(10 \mathrm{mM})$, followed by incubation at $37^{\circ} \mathrm{C}$ for $1 \mathrm{~h}$. An aliquot of $1.0 \mathrm{ml}$ of the incubated mixture was mixed with $1.0 \mathrm{ml}$ of $10 \%$ trichloro acetic acid and $1.0 \mathrm{ml}$ of $0.5 \%$ thio barbituric acid (in $0.025 \mathrm{M} \mathrm{NaOH}$ ) to develop the pink chromogen measured at $532 \mathrm{~nm}$. The hydroxyl radical scavenging activity of the extract is reported as \% inhibition of deoxy ribose degradation.

\section{DPPH radical scavenging activity}

The radical scavenging activity of extract was measured using $\mathrm{DPPH}{ }^{*}$ stable radical. ${ }^{21}$ As per standards, the reaction mixture contains methanol extract of sample $(0.1 \mathrm{ml})$ and $2.9 \mathrm{ml}$ of freshly prepared DPPH solution $\left(6 \times 10^{-5} \mathrm{M}\right)$. The mixture was then shaken vigorously before incubation for a period of $30 \mathrm{~min}$ in dark at $27^{\circ} \mathrm{C}$. The decrease in absorbance at $517 \mathrm{~nm}$ was recorded and the results were expressed in terms of concentration required for $50 \%$ inhibition of DPPH radical by test sample as $\mathrm{IC}_{50}(\mathrm{mg} / \mathrm{ml})$. Quercetin is used as positive control having similar treatment protocol as mentioned above.

\section{In vitro anti arthritic activity}

Inhibition of protein denaturation

Inhibition of protein denaturation by test extract was evaluated by the method with slight modification..$^{22,23} 450 \mu \mathrm{L}$ of Bovine Serum Albumin ( $5 \%$ aq. Solution) was added to $50 \mu \mathrm{L}$ of test solution (methanol extract, $0.05 \mathrm{mg} / \mathrm{ml}$ ). The reaction mixture was kept at $37^{\circ} \mathrm{C}$ for $30 \mathrm{~min}$, followed by heating at $50^{\circ} \mathrm{C}$ for $10 \mathrm{~min}$. In the resulting solution $2.5 \mathrm{ml}$ of phosphate buffer ( $\mathrm{pH}$ 6.5) was added and allowed to cool down at room temperature, absorbance was than recorded at $660 \mathrm{~nm}$. Acetyl salicylic acid was taken as a positive control. The experiment was carried out in triplicates and percent inhibition for protein denaturation was calculated using, \% Inhibition $\left.=100-\left(\left(A_{t}-A_{c}\right) / A_{t}\right)^{\star} 100\right)$. Where $A_{t}$ is the absorbance of the sample, Ac is the absorbance of the product control.

\section{Statistical analysis}

Results were reported as means \pm standard deviation (S.D) of three replicates of the same extract. Data were subjected to one-way analysis of variance (ANOVA) to test the level of significance (XLSTAT, 2010, Microsoft Corporation, USA). The cluster analysis was done by PAST 2.15 for the selection of elite chemotypes and clustering of samples.

\section{RESULTS}

\section{HPTLC quantification of colchicine}

Seven germplasm of G. superba (tuber) were collected from the phytogeographical region of Eastern Himalayas of India, exhibiting the altitudinal variation from 94.48 to 1162.812 meter Table 1 . Chemical profiling and method optimization for quantification of colchicine were carried out on $20 \mathrm{~cm} \times 10 \mathrm{~cm}$ TLC aluminum precoated plates with $200 \mathrm{~nm}$ layer thickness of silica gel $60 \mathrm{~F}_{254}$ (SD. Fine-Chem Ltd., Mumbai, India). Tracks (standard and sample) were applied as $6 \mathrm{~mm}$ bandwidth using Camag $100 \mu \mathrm{l}$ sample syringes (Hamilton, Switzerland) with a Linomat 5 applicator (Camag, Switzerland) under a flow of $\mathrm{N}_{2}$ gas. The linear ascending development was carried out with chloroform: acetone: diethylamine $(5: 4: 1 \mathrm{v} / \mathrm{v} / \mathrm{v})$ as a mobile phase in a Camag glass twin trough chamber. $^{24}$

After development, the plates were air dried for $30 \mathrm{~min}$, and scanning was performed using Camag TLC Scanner 3 at $\lambda_{\text {max }}$ of $350 \mathrm{~nm}$ in UV absorbance-reflectance mode operated by win CATS software (version 3.2.1) for the colchicines content. Quantification was performed using regression analysis of peak area versus concentration of standard marker in the range of 100-400 $\mathrm{ng} /$ band having statistically, acceptable regression coefficient $\left(\mathrm{r}^{2}\right)$ of 0.9987 . The slope and intercept of linear line was 14.837 and 417.63 with statistically acceptable LOD and LOQ Table 2. Quantification data (\% dry wt. of sample) reveal that the content of colchicine varies from 0.044 to $0.184 \%$ Figure 1, maximum content was observed in NBG-128 from Jorhat, Assam. While minimum content of colchicine was observed in NBG-24 and NBG-25 from 6th mile, Kalimpong, Darjeeling and Kalimpong, West Bengal.

\section{Identification of elite chemotype}

Hierarchical cluster analysis was performed to group the samples on basis of colchicine content and altitude in seven samples (Hammer et al. 2001) as other biotic and abiotic factors are considered salient within the same phytogeography of Eastern Himalayas. A UPGMA dendrogram Figure 2 reveals that the whole population was divided into two branches, clustering NBG-23, NBG-24 and NBG-25 into one branch (I), whereas NBG-26, NBG-27, NBG-52 and NBG-128 into other one (II).

Branch II was further bifurcated and separating the one germplasm, NBG-128 as elite chemotype having highest content of colchicine. Beside this, NBG-23 and NBG-24 having lowest content of metabolite was also selected with an approach that the pharmacological response may be due 
Table 1: GPS information of collected samples of Gloriosa superba.

\begin{tabular}{ccccccc}
\hline Collection code & $\begin{array}{c}\text { Voucher } \\
\text { No. }\end{array}$ & $\begin{array}{c}\text { Places/location/ } \\
\text { District }\end{array}$ & Height (feet) & Latitude (N) & Longitude (E) & Soil type \\
\hline NBG-23 & 305323 & 3rd mile Kalimpong/ Darjeeling/W.B & 1162.812 & $27^{\circ} 03^{\prime} 28.72^{\prime \prime}$ & $88^{\circ} 27^{\prime} 35.47^{\prime \prime}$ & Red gravel hilly soil \\
NBG-24 & 305324 & 6th mile, Kalimpong/ Darjeeling/W.B & 1162.812 & $27^{\circ} 03^{\prime} 28.72^{\prime \prime}$ & $88^{\circ} 27^{\prime} 35.47^{\prime \prime}$ & Red gravel hilly soil \\
NBG-25 & 305325 & Kalimpong/W.B & 1162.812 & $27^{\circ} 03^{\prime} 36.00^{\prime \prime}$ & $88^{\circ} 28^{\prime} 12.00^{\prime \prime}$ & Red gravel hilly soil \\
NBG-26 & 305326 & Sumbuk/ W. Sikkim & 359.664 & $27^{\circ} 05^{\prime} 54.93^{\prime \prime}$ & $88^{\circ} 22^{\prime} 51.81^{\prime \prime}$ & Red gravel hilly soil \\
NBG-27 & 305327 & Jorethang/W. Sikkim & 321.25 & $27^{\circ} 07^{\prime} 55.88^{\prime \prime}$ & $88^{\circ} 16^{\prime} 53.02^{\prime \prime}$ & Red gravel hilly soil \\
NBG-52 & 305352 & Itanagar, Arunanchal Pradesh & 296.87 & $27^{\circ} 05^{\prime} 12.84^{\prime \prime}$ & $93^{\circ} 36^{\prime} 31.00^{\prime \prime}$ & Red soil \\
NBG-128 & 307928 & Jorhat, Assam & 94.48 & $26^{\circ} 44^{\prime} 47.47^{\prime \prime}$ & $94^{\circ} 12^{\prime} 09.31^{\prime \prime}$ & Red gravel hilly soil \\
\hline
\end{tabular}

W.B: West Bengal, AAU: Assam Agriculture University

Table 2: Statistical parameter for linearity calibration of standard colchicine

\begin{tabular}{cc}
\hline Statistical parameters* & Colchicine \\
\hline $\mathrm{R}_{\mathrm{f}}$ & 0.71 \\
$\mathrm{r}^{2}$ & 0.9987 \\
Slope & 14.837 \\
Intercept & 417.63 \\
LOD (ng) & 6.245 \\
LOQ (ng) & 18.926 \\
RSD (\%) & 0.715 \\
\hline
\end{tabular}

${ }^{\star} \mathrm{n}=3, \mathrm{r}^{2}$ : regression coefficient

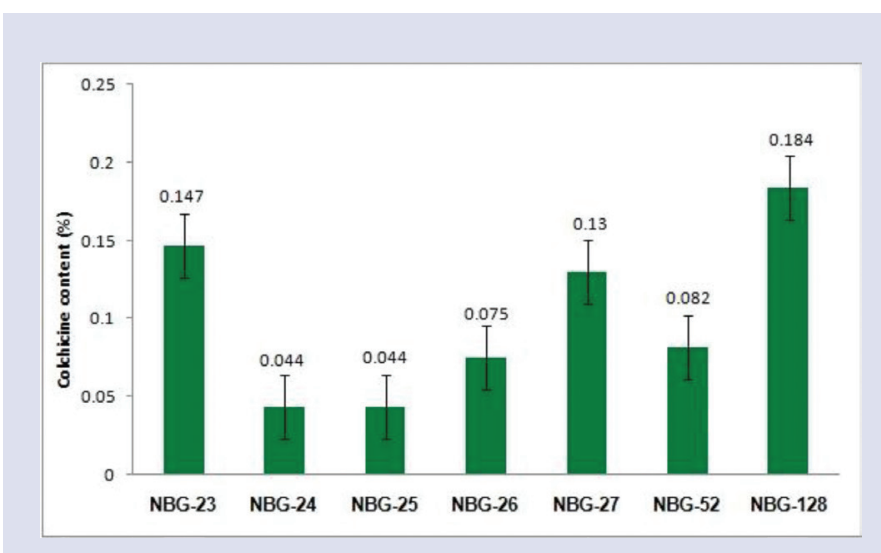

Figure 1: HPTLC quantification of colchicine in G. superba samples collected from Eastern Himalayas.

to synergistic effect and not exclusively due to colchicine content. Thus, three germplasm NBG-24, NBG-25 and NBG-128 are selected for in vitro anti-arthritic activity.

\section{Total polyphenolic content}

All the seven samples were quantatively analysed though spectrophotometric method for the estimation total phenolic (TPC) and flavonoid content (TFC) in extract and results reveal that there is significant difference within the samples. The total phenolic content in extract(s) was estimated against calibration curve of standard Gallic acid $(0.1 \mathrm{mg} / \mathrm{ml})$ at concentration range of $20-100 \mu \mathrm{l}$ using regression equation; $y=95.54 x+0.384$ and coefficient of 0.989 . Whereas, total flavonoid content was calculated against calibration curve of quercetin $(0.01 \mathrm{mg} / \mathrm{ml})$ at variable dilutions of $0.2-0.5 \mu \mathrm{l}$, using regression equation; $\mathrm{y}=74.61 \mathrm{x}$

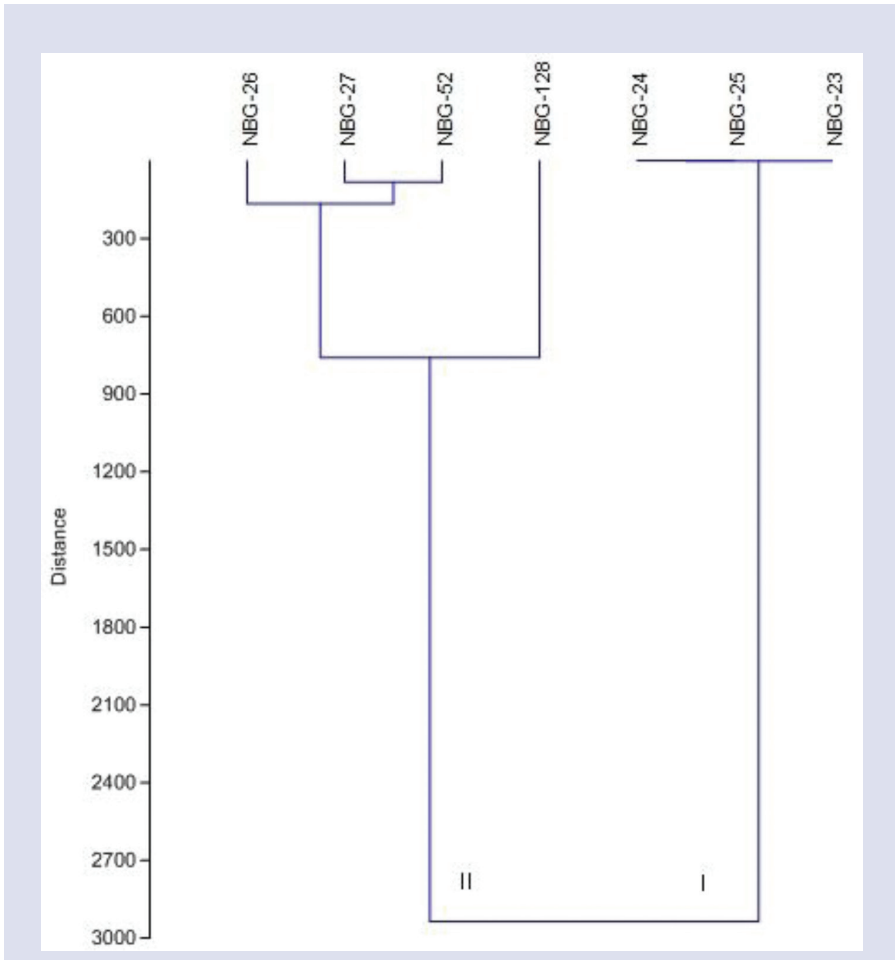

Figure 2: UPGMA dendogram of G. superba germplasm collected from Eastern Himalayas on basis of Colchicine content and altitude for identification of elite chemotypes.

+0.058 and $r^{2}=0.998$. The TPC ranges from 0.3 to $2.95 \%$, maximum content was in NBG- 25 (Kalimpong, W.B) and minimum was in NBG-52 (Itanagar, Arunanchal Pradesh). The TFC varies from 0.0074 to $0.0335 \%$, maximum was in NBG- 27 (Jorethang, West Sikkim) and minimum in NBG-24 from 6th mile Kalimpong, Darjeeling, West Bengal Figure 3.

A cluster analysis Figure 4 was performed to segregate the population based on TPC and TFC for identification of elite germplasm, UPGMA dendogram was constructed and it was observed that the population was divided into two branches (I and II). Branch one was further divided to separate NBG-23, NBG-24 and NBG-52 into one group. The other arm (II) of dendogram contains four germplasm among which NBG-25 was distinctively separated out as elite germplasm with considerably higher content of both TPC and TFC.

\section{Variability in anti-arthritic and antioxidant activity}

The selected elite germplasm (based on colchicine and polyphenolic content) viz. NBG-24, NBG-25 and NBG-128 were evaluated for anti- 


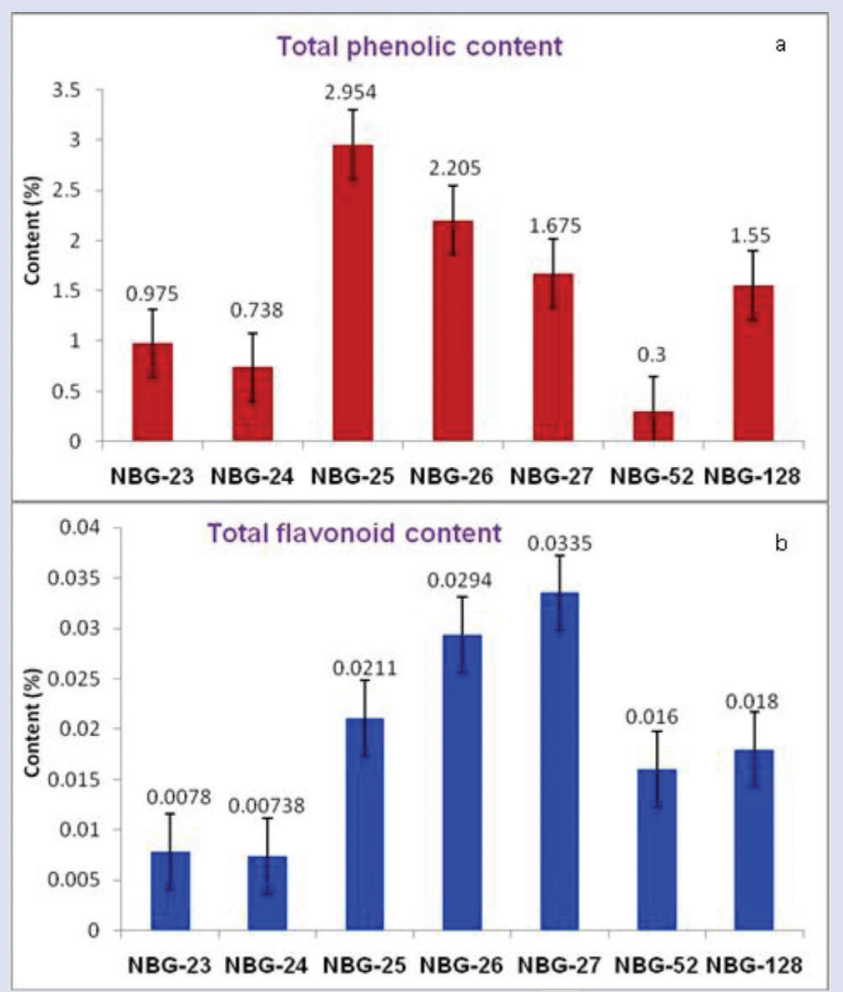

Figure 3: Total phenolic (TPC) and Flavonoid content (TFC) of G. superba germplasm.

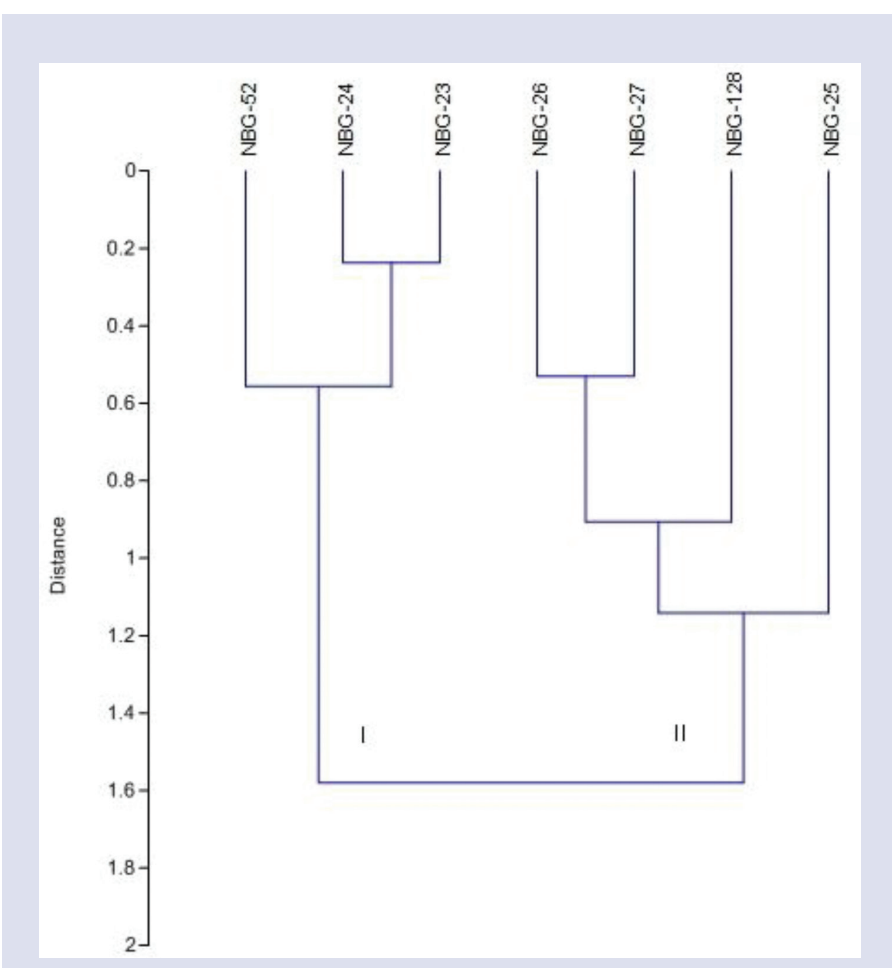

Figure 4: UPGMA dendogram of G. superba germplasm collected from Eastern Himalayas on basis of TPC and TFC. arthritic potential. In addition to this, radical scavenging potential via DPPH radical scavenging and hydroxyl radical scavenging assay was also checked. The anti-arthritic potential of elite germplasm was analyzed by inhibition of protein denaturation of Bovine serum albumin, with increase in concentration of test extract the denaturation of albumin protein decreases characteristically. At a concentration range of 0.001 to $0.005 \mathrm{mg} / \mathrm{ml}$, the inhibition (\%) in NBG-24, NBG-25 and NBG-128 varies from 25.81 to $67.66 \%, 23.21$ to $60.18 \%$ and 28.33 to $64.46 \%$ respectively with $\mathrm{IC}_{50}$ at $0.0031,0.004,0.0032 \mathrm{mg} / \mathrm{ml}$ respectively. Pure colchicine under the identical in vitro experimental condition exhibit an $\mathrm{IC}_{50}$ at $0.0048 \mathrm{mg} / \mathrm{ml}$, at a concentration range of 0.001 to $0.005 \mathrm{mg} / \mathrm{ml}$. Aspirin, the positive control of study exhibit the maximum inhibition of $74.64 \%$ at concentration of $200 \mu \mathrm{g} / \mathrm{ml}$ with regression coefficient of 0.989 .

The elite germplasm was found to have promising radical (Hydroxyl) scavenging activity when tested under standardized protocol. The DPPH radical scavenging assay was performed under the mentioned protocol at stock concentration of $2 \mathrm{mg} / \mathrm{ml}$, the $\mathrm{IC}_{50}$ of elite germplasm NBG-24, NBG-25 and NBG-128 was at 2.18, 1.62 and $0.531 \mathrm{mg} / \mathrm{ml}$ respectively. The inhibition (\%) of DPPH free radical by test extract of elite germplasms varies from 1.77 to $8.6 \%, 4.08$ to $20.18 \%$ and 10.53 to 44.52 $\%$ for NBG-24, NBG-25 and NBG-128 respectively. The calibration curve of elite sample was documented in supplementary Figure 1. The Inhibition (\%) of quercetin ranges from 12.77 to $72.43 \%$ at a concentration range of 0.002 to $0.026 \mathrm{mg} / \mathrm{ml}$. $\mathrm{IC}_{50}$ of quercetin was recorded at 5.95 $\pm 0.115 \mu \mathrm{g} / \mathrm{ml}$. In the other assay, the hydroxyl radical scavenging activity of elite germplasm were evaluated at stock concentration of $0.05 \mathrm{mg} / \mathrm{ml}$, exhibit a statistically significant regression coefficient Supplementary Figure 2. The inhibition (\%) of hydroxyl radical in elite sample varies from 25.81 to $67.66 \%, 23.21$ to $60.18 \%$ and 28.33 to $64.46 \%$ for NBG-24, NBG-25 and NBG-128 having $\mathrm{IC}_{50}$ at $0.0029,0.0048$ and $0.003 \mathrm{mg} / \mathrm{ml}$ respectively. The scavenging activity of quercetin standard (positive control) at a concentration range of $20-100 \mu \mathrm{g} / \mathrm{ml}$ varies from 10.03 to $82.15 \%$ with an $\mathrm{IC}_{50}$ value of $41.05 \mu \mathrm{g} / \mathrm{ml}$.

\section{DISCUSSION}

It is well evident that the use of Gloriosa superba in gout is due to action of colchicine on several biochemical reactions, majorly on inflammatory mediators. The effect is multifacet and involves at molecular level underlying the cascade of inflammatory action. Specifically, it is attributed due to various proposed actions as disruption of microtubule in neutrophils and inhibiting their migration towards the chemotactic factors, alteration in distribution of adhesion molecules on the surface of both neutrophils and endothelial cells, which significantly inhibit the interaction between WBC and endothelial cells, inhibition of monosodium urate crystal activation of the NLRP3 inflammasome, inhibit the release of IL- $1 \beta$ and suppression of gene expression. ${ }^{12,13,14,15}$ This however is dependent upon the dose of colchicine and duration of treatment; the effect is at both molecular and genetic level. ${ }^{25}$ The competitive binding of colchicine to serum albumin was well established ${ }^{26}$ and thus supports the selection of appropriate method in study to check the existing variability in targeted pharmacological activity.

Quantification data reveals significant variation in the colchicine content of collected samples, among which NBG-128 was statistically selected as the elite chemotype with high colchicine content. However pharmacological response of anti arthritic activity was not significantly varied in selected three elite chemotypes viz. NBG-24, NBG-25 and NBG-128. Moreover, the elite germplasm(s) exhibit more prominent anti-arthritic activity than pure colchicine and thus we presumed that this may be due to synergistic action of other unknown metabolites along with colchicine in extract for such potentiating response towards the inhibition of pro- 
tein denaturation. The results of radical scavenging assays were variable but pronounced in elite germplasm. Thus, there may be a possibility that the inhibition of inflammatory mediators will be more accentuated when whole extract of $G$. superba is used in the form of herbal medicine/formulation than pure colchicine, especially in cases of long term treatment considering the toxicity factor of species. As in such cases anti inflammatory action of colchicine is super imposed with the anti oxidant action of other polyphenolics present in extract.

\section{CONCLUSION}

Seven germplasm were collected from different location of Eastern Himalayas up to an altitude of 1162.812 meters. A calibrated HPTLC method was used to quantify colchicine in collected samples, ranging from 0.044 to $0.184 \%$ having maximum content in NBG-128 from Jorhat, Assam. While minimum content of colchicine of observed in NBG-24 and NBG-25 from 6th mile, Darjeeling, W.B. and Kalimpong, W.B. Germplasm from Jorhat, Assam (NBG-128) was statistically screened as elite chemotype with highest colchicine content. Three germplasm viz. NBG-24, NBG-25 and NBG-128 with highest and lowest colchicine content was pharmacologically validated. The test extracts reflect potential anti arthritic activity with promising hydroxyl radical scavenging activity in addition with no statistically significant difference within the selected germplasm. The results, thus suggested that the effect of Gloriosa superba whole extract on curbing the inflammation causing cells is more pronounced than pure colchicine and which may due to superimposed action of colchicine and, other chemical inhibitors like polyphenolics. Thus, it will aid in site specific exploration and commercial cultivation of high metabolite yielding chemotype(s) with validated pharmacological action to meet out the medicinal and commercial demands of colchicine. This will also promote the use of species in herbal product development as an adjuvant therapy in acute gouty flare for inhibition of inflammation.

\section{ACKNOWLEDGEMENT}

The authors are thankful to the Director, CSIR-National Botanical Research Institute, Lucknow for providing necessary facilities during the experiment. Authors are also thankful to NASF, ICAR for financial support to this project and Faculty of Pharmacy, Integral university for Ph. D course affiliation (MCN no. IU/R\&D/2017-MCN000182) and execution to senior author (Ms Ankita Misra)".

\section{CONFLICT OF INTEREST}

Authors do not have any conflict of Interest.

\section{REFERENCES}

1. Warrier PK, Nambiar VPK, Ramankutty C. In Vaidua et al., (Eds.). Indian Medicinal Plants. Orient Longman. 1995;(3):76-81.

2. Maroyi A, Van der Maesen LJG. Gloriosa superba L. (family Colchicaceae): Remedy or poison? J Med Plants Res. 2011;5(26):6112-21.

3. Hemaiswarya S, Raja R, Anbazhagan C, Thiagarajan V. Antimicrobial and mutagenic properties of the root tubers of Gloriosa superba L. (kalihari). Pak J Bot. 2006;41(1):293-9.

4. Haroon RB, Nagarajan N. Antibacterial potential of glory lilly, Gloriosa superba. Inter Res J Pharm. 2011;2(3):139-42.
5. Srivastava UC, Chandra V. Gloriosa superba I. (kalihari) - an important colchicines producing plant. J Res Indian Med. 1977;10:92-5.

6. Prajapati ND, Purohit SS, Sharma AK, KumarT. A hand book of medicinal plants. Agro Bios Publishers, Jodhpur. India. 2003;221-34

7. Bharathi P, Philomina D, Chakkaravarthi S. Estimation of colchicine in six different species of Gloriosa grown in vivo. Indian J Pharm Sci. 2006;68(6):806-9.

8. Soni N, Patidar P, Dubey D, Dashora K, A Validated HPTLC Method for Determination of Colchicine in Gloriosa superba collected from different regions of India, J Pharm Res. 2012;5(7):3858-9.

9. Basak UC, Dash D, Mahapatra AK. Estimation of colchicine in tubers of Gloriosa superba I. originated from different agroclimatic zones of Odisha, India. Inter J Pharmacognosy Phytochemical Res. 2012;4(3):157-61.

10. Srivastava S, Misra A, Shukla PK, Kumar B, Lata S, Rawat AKS. A validated over pressured layered chromatography (OPLC) method for separation and quantification of colchicine in Gloriosa superba (L.) tubers from different geographical regions. RSC Adv. 2014;4:60902-6.

11. Raimond BGR, Gigant B, Curmi PA, Jourdain I, Lachkar S, Sobel A, et al. Insight into tubulin regulation from a complex with colchicine and a stathmin-like domain. Nature. 2004;428(6979):198-202.

12. Martinon F, Petrilli V, Mayor A, Tardivel A, Tschopp J. Gout-associated uric acid crystals activate the NALP3 inflammasome. Nature. 2006;440(7081):237-41.

13. Misawa T, Takahama M, Kozaki T, Lee H, Zou J, Saitoh T, et al. Microtubule-driven spatial arrangement of mitochondria pro- motes activation of the NLRP3 inflammasome. Nat Immunol. 2013;14(5):454-60.

14. Ding AH, Porteu F, Sanchez E, Nathan CF. Down regulation of tumor necrosis factor receptors on macrophages and endothelial cells by microtubule depolymerizing agents. J Exp Med. 1990;171(3):715-27.

15. Cronstein BN, Molad Y, Reibman J, Balakhane E, Levin RI, Weissmann G. Colchicine alters the quantitative and qualitative display of selectins on endothelial cells and neutrophils. J Clinical Invest. 1995;96(2):994-1002.

16. Latha KP, Kirana H, Girish HN. Anti-implantation activity of the hydroalcoholic tuber extract of Gloriosa superba L. in female albino rats. Inter J Res Pharm Chem. 2103;2(3):662-7.

17. International Conference on Harmonization (ICH) of Technical Requirements for Registration of Pharmaceuticals for Human use, Harmonised Triplicate Guideline on Validation of Analytical Procedures: Text and Methodology Q2 (R1). Complementary Guideline on Methodology incorporated in November 2005 by the $\mathrm{ICH}$ Steering Committee, IFPMA, Geneva.

18. Bray HG, Thorpe WV. Analysis of phenolic compounds of interest in metabolism Meth Biochemical Anal. 2006;1:27-52.

19. Ordonez AA, Gomez JD, Vattuone MA, Isla MI. Antioxidant activities of Sechium edule (Jacq.) swart extracts. Food Chem. 2006;97(3):452-8. https://doi. org/10.1016/j. food chem. 2005.05.024.

20. Halliwell B, Gutteridge JM, Aruoma O. The deoxiribose method: a simple test to be assay for determination of rate constants for reaction of hydroxyl radicals. Ana. Biochemical. 1987;165(1):215-9. https://doi.org/10.1016/00032697(87)90222-3.

21. Yen GC, Duh PD, Scavenging Effect of Methanolic Extracts of Peanut Hulls on Free-Radical and Active-Oxygen Species. J Agric Food Chem. 1994;42(3):629-32.

22. Mizushima $Y$, Kobayashi $M$, Interaction of anti-inflammatory drugs with serum proteins, especially with some biologically active proteins. J Pharm Pharmacology. 1968;20(3):169-73.

23. Sakat S, Juvekar AR, Gambhire MN. In vitro antioxidant and anti-inflammatory activity of methanol extract of Oxalis corniculate Linn. Inter J Pharm Pharma Sci. 2010;2(1):146-56.

24. Misra A, Shukla PK, Kumar B, Chand J, Kushwaha P, Khalid M, et al. High-performance thin-layer chromatographic-densitometric quantification and recovery of bioactive compounds for identification of elite chemotypes of Gloriosa superba L. collected from Sikkim Himalayas (India). Phcog Mag. 2017;13:S700-5.

25. Ben-Chetrit E, Bergmann S, Sood R. Mechanism of the anti-inflammatory effect of colchicine in rheumatic diseases: a possible new outlook through microarray analysis. Rheumatology. 2006;45(3):274-82.

26. Sulkowska A, Maciazek-Jurczyka M, Bojko B, Rownicka J, Zubik-Skupien I, Temba E. et al. Competitive binding of phenylbutazone and colchicine to serum albumin in multidrug therapy: A spectroscopic study. J Mole Structure. 2008:881(1-3):97-106. 
GRAPHICAL ABSTRACT

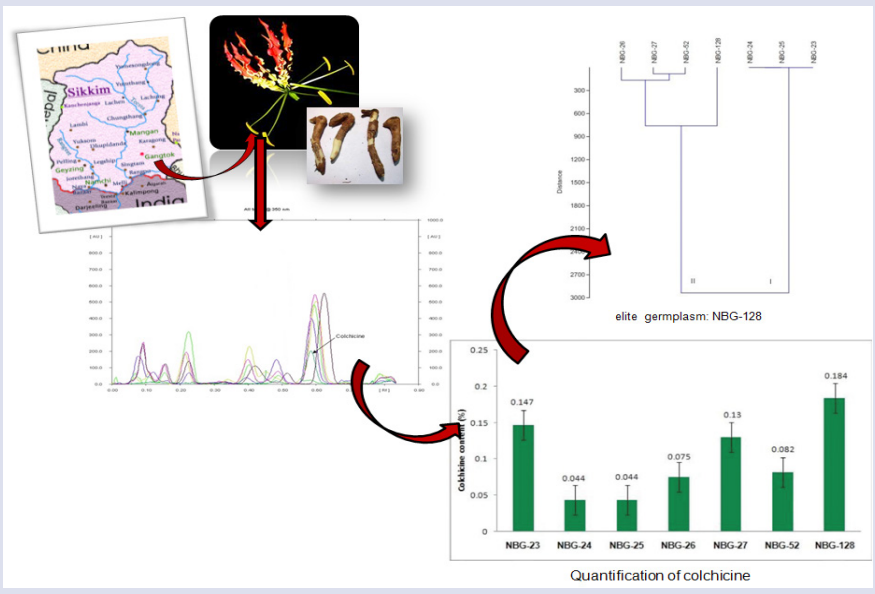

\section{SUMMARY}

- Seven germplasm were collected from different location of Eastern Himalayas up to an altitude of 1162.812 meters.

- A calibrated HPTLC method was used to quantify colchicine content in samples, ranging from 0.044 to $0.184 \%$ having maximum content in NBG-128 from Jorhat, Assam.

- The test extracts reflect potential anti arthritic activity in addition with promising hydroxyl radical scavenging activity.

- The results, thus suggested that the effect of Gloriosa superba whole extract on curbing the inflammation causing cells is more pronounced than pure colchicine and which may due to superimposed action of colchicine and, other chemical inhibitors like polyphenolics.

- This will aid in site specific exploration and commercial cultivation of high metabolite yielding chemotype(s) with validated pharmacological action to meet out the medicinal and commercial demands of colchicine.

\section{ABOUT AUTHORS}

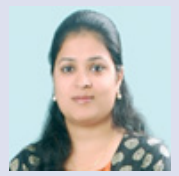

Ms. Ankita Misra: Is working as a Research Associate in Pharmacognosy Division at CSIR-National Botanical Research Institute; Lucknow, INDIA. She is working in the area of analytical chemistry on medicinal plants, chemotaxonomy, bio-prospection and natural product development, handling major analytical instruments including HPLC, HPTLC, OPLC and column chromatography for quality control of herbal drugs. She has 23 publications in peer reviewed journals and 1 patent is.

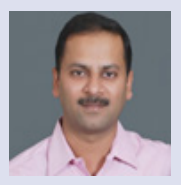

Dr. Sharad Srivastava: Is Principal Scientist in Pharmacognosy Division at CSIR-National Botanical Research Institute; Lucknow, INDIA. He has made significant contributions to quality control of crude drugs/products, chemotaxonomy, bio-prospection and natural product develop $\neg$ ment and have developed quality parameters of single crude drugs (more than 70 medicinal plants) and also identified biomarkers for their quality control. He has contributed 30 monographs of single herbal drugs in Ayurvedic Pharmacopoeia of India. He has 135 publications in peer reviewed journals, 17 patents and developed some technologies/formulations, few has already been transferred to industry.

Cite this article: Misra A, Srivastava A, Khalid M, Kushwaha P, Srivastava S. Evaluation of Anti Arthritic Potential of Gloriosa superba (L.) Elite Germplasm Collected from Eastern Himalayas, India. Pharmacog J. 2017;9(6):s87-s92. 